\title{
L'utilisation d'extrait de Cynara cardunculus $L$. comme agent coagulant en fabrication de fromages à pâte molle et à pâte cuite
}

\author{
par \\ Manuela BARBOSA* \\ E. VALLES, L. VASSAL et G. MOCQUOT** \\ avec la collaboration technique de M. NICOLAS, G. PITEL \\ et J. C. VACHOT
}

Une étude assez récente [1] a été consacrée à la fabrication artisanale des fromages de Serra et de Serpa qui s'effectue au Portugal depuis des siècles à l'aide d'un extrait coagulant obtenu à partir des fleurs de Cynara cardunculus L. D'autres travaux ont été réalisés sur les caractéristiques de l'enzyme coagulante de la fleur de Cynara cardunculus $[2,3]$.

Le but de notre travail actuel était d'étudier l'influence de cet extrait coagulant sur la technologie de fabrication, la qualité et les propriétés des fromages de Camembert et de Gruyère****.

\section{MATERIEL ET METHODES}

\section{1) Lait}

Le lait utilisé pour les fabrications provenait du troupeau de vaches de race française Frisonne Pie Noire - F.F.P.N. - du domaine expérimental de l'I.N.R.A. à Bressonvillers. Le lait était conservé à la ferme pendant environ $17 \mathrm{~h}$ pour le lait du soir et

* Instituto Nacional de Investigaçao Industrial (I.N.I.I.), Lisboa-6 (Portugal). Boursière de l'A.C.T.I.M.

** Station Centrale de Recherches Laitières et de Technologie des Produits animaux C.N.R.Z.-I.N.R.A. - 78350 Jouy-en-Josas (France).

*** Ce travail fait partie d'un programme de recherches entreprises par la Section des Industries Laitières du Département de Technologie Agricole du I.N.I.I. portugais, sur l'emploi de l'extrait coagulant de Cynara cardunculus en fromagerie. 
$3 \mathrm{~h}$ pour le lait du matin, en réservoir réfrigérant réglé à $4^{\circ} \mathrm{C}$. Il était ensuite conservé cru à la Laiterie Expérimentale à l'I.N.R.A. à Jouy-en-Josas pendant $20 \mathrm{~h}$ entre $4^{\circ} \mathrm{C}$ et $6^{\circ} \mathrm{C}$.

La teneur en graisse du lait de fabrication était ajustée par écrémage d'une partie du lait au début de la conservation à la Laiterie. Le tableau 1 pour le Camembert et le tableau 2 pour le Gruyère résument les principales caractéristiques du lait de fabrication.

\section{2) Enzymes coagulantes}

Une présure liquide du commerce* de force environ 10000 préparée à partir de caillette de veaux et utilisée habituellement à la Laiterie Expérimentale, servait à la fabrication des fromages témoins.

L'extrait de Cynara cardunculus utilisé pour les fabrications de Camembert était un extrait liquide tandis que le Gruyère était fabri-

TABLEAU 1. - Caractéristiques du lait de fabrication « Camembert »

\begin{tabular}{|c|c|c|c|}
\hline Essai & 1 & 2 & 3 \\
\hline $\begin{array}{l}\text { Qualité bactériologique } \\
\text { (nombre de germes } / \mathrm{ml} \text { ) }\end{array}$ & & & \\
\hline $\begin{array}{l}\text { Flore totale } \\
\text { Lait cru Coliformes } \\
\text { Clostridia }\end{array}$ & $\begin{array}{l}6,9 \cdot 10^{4} \\
6,4 \cdot 10^{3} \\
<0,2\end{array}$ & $\begin{array}{l}3,0.10^{4} \\
2,4 \cdot 10^{3} \\
<0,2\end{array}$ & $\begin{array}{r}10,1 \cdot 10^{1} \\
7,0.10^{3} \\
<0,2\end{array}$ \\
\hline $\begin{array}{c}\text { Composition du lait standardisé } \\
\text { Graisse }(\mathrm{g} / \mathrm{kg}) \\
\text { Matière azotée }(\mathrm{g} / \mathrm{kg})\end{array}$ & $\begin{array}{l}29,1 \\
31,4\end{array}$ & $\begin{array}{l}28,2 \\
32,0\end{array}$ & $\begin{array}{l}28,6 \\
32,4\end{array}$ \\
\hline $\begin{array}{l}\text { Traitements } \\
\text { Pasteurisation } \\
\text { Phosphatase }\end{array}$ & $\begin{array}{l}72^{\circ} \mathrm{C}-15 \mathrm{~s} \\
\text { négative }\end{array}$ & $\begin{array}{l}72^{\circ} \mathrm{C}-15 \mathrm{~s} \\
\text { négative }\end{array}$ & $\begin{array}{l}72^{\circ} \mathrm{C}-15 \mathrm{~s} \\
\text { négative }\end{array}$ \\
\hline $\begin{array}{l}\text { Produits d'addition : } \\
\qquad- \text { Levain lactique }\end{array}$ & $\begin{array}{l}\text { suspension } \\
\text { concentrée }\end{array}$ & $\begin{array}{l}\text { suspension } \\
\text { concentrée }\end{array}$ & $\begin{array}{l}\text { suspension } \\
\text { concentrée }\end{array}$ \\
\hline - nature & $\begin{array}{l}\text { Str. lactis } \\
272+\text { Str. } \\
\text { cremoris } 112\end{array}$ & $\begin{array}{l}\text { Str. lactis } \\
304+\text { Str. } \\
\text { cremoris } 116\end{array}$ & $\begin{array}{l}\text { Str. lactis } \\
272+\text { Str. } \\
\text { cremoris } 112\end{array}$ \\
\hline - inoculum & 1 p. 1000 & 0,2 p. 1000 & 0,2 p. 1000 \\
\hline
\end{tabular}

* Présure fabriquée par la Filiale Française de Hansen - Ets Boll - 94 Vincennes. 
TABLEAU 2. - Caractéristiques du lait de fabrication " Gruyère "

\begin{tabular}{|c|c|c|c|}
\hline Essai & 1 & 2 & 3 \\
\hline $\begin{array}{c}\text { Qualité bactériologique } \\
\text { (nombre de germes/ml) } \\
\text { Flore totale } \\
\text { Coliformes } \\
\text { Clostridia }\end{array}$ & $\begin{array}{l}5,7.10^{4} \\
4,5 \cdot 10^{3} \\
<0,2\end{array}$ & $\begin{array}{l}3,4 \cdot 10^{4} \\
2,5 \cdot 10^{3} \\
<0,2\end{array}$ & $\begin{array}{l}9,0.10^{4} \\
7,0.10^{3} \\
<0,2\end{array}$ \\
\hline $\begin{array}{c}\text { Composition du lait standardisé } \\
\text { Graisse }(\mathrm{g} / \mathrm{kg}) \\
\text { Matière azotée }(\mathrm{g} / \mathrm{kg})\end{array}$ & $\begin{array}{l}34,0 \\
33,6\end{array}$ & $\begin{array}{l}32,0 \\
33,5\end{array}$ & $\begin{array}{l}32,0 \\
33,5\end{array}$ \\
\hline $\begin{array}{l}\text { Additions } \\
\text { Levain lactique }\end{array}$ & & & \\
\hline $\begin{array}{c}\text { — mésophiles } \\
\text { • nature }\end{array}$ & $\begin{array}{l}\text { culture } \\
\text { sur lait }\end{array}$ & $\begin{array}{l}\text { culture } \\
\text { sur lait }\end{array}$ & $\begin{array}{l}\text { culture } \\
\text { sur lait }\end{array}$ \\
\hline $\begin{array}{c}\text { - inoculum } \\
\text { - thermophiles }\end{array}$ & $0,6 \mathrm{p} \cdot 100$ & 0,6 p. 100 & 0,6 p. 100 \\
\hline - nature & $\begin{array}{c}\text { suspension } \\
\text { concentrée } \\
\text { L. helveticus } \\
\text { S. thermophilus }\end{array}$ & $\begin{array}{c}\text { suspension } \\
\text { concentrée } \\
\text { L. helveticus } \\
\text { 5. thermophilus }\end{array}$ & $\begin{array}{l}\text { suspension } \\
\text { concentrée } \\
\text { L. helveticus } \\
\text { S. thermophilus }\end{array}$ \\
\hline $\begin{array}{c}\text { - inoculum } \\
\text { - propioniques }\end{array}$ & 0,02 p. 1000 & 0,02 p. 1000 & 0,02 p. 1000 \\
\hline - nature & $\begin{array}{c}\text { CNRZ } 88 \text { sur } \\
\text { lait }\end{array}$ & $\begin{array}{c}\text { CNRZ } 88 \text { sur } \\
\text { lait }\end{array}$ & $\begin{array}{c}\text { CNRZ } 88 \text { sur } \\
\text { lait }\end{array}$ \\
\hline - inoculum & 0,1 p. 1000 & 0,1 p. 1000 & 0,1 p. 1000 \\
\hline
\end{tabular}

qué avec un extrait en poudre. Au moment de l'emploi, on préparait à partir de la poudre une solution aqueuse, en dissolvant le poids de poudre nécessaire à la fabrication dans 11 d'eau environ. Cette poudre était difficilement soluble. Sa solution dans l'eau était, de même que l'extrait liquide proprement dit, de couleur brun foncé et présentait en outre comme l'extrait liquide une saveur très amère.

\section{3) Méthodes de fabrication}

CAMEMBERT : Après pasteurisation, $100 \mathrm{~kg}$ de lait étaient ensemencés à l'aide de suspensions concentrées congélées de bactéries lacti- 
TABLEAU 3. - Camembert (conditions de fabrication)

\begin{tabular}{|c|c|c|c|c|c|c|}
\hline \multirow[b]{2}{*}{ Essai } & \multicolumn{2}{|c|}{1} & \multicolumn{2}{|c|}{2} & \multicolumn{2}{|c|}{3} \\
\hline & Présure & $\begin{array}{l}\text { Cynara } \\
\text { cardunculus }\end{array}$ & Présure & $\begin{array}{l}\text { Cynara } \\
\text { cardunculus }\end{array}$ & Présure & $\begin{array}{l}\text { Cynara } \\
\text { cardunculus }\end{array}$ \\
\hline Quantité de lait (kg) & 50 & 50 & 50 & 50 & 50 & 50 \\
\hline $\begin{array}{l}\text { Inoculation des levains } \\
\text { pH du lait } \\
\text { Acidité }\left({ }^{\circ} \mathrm{D}\right) \\
\text { Température }\left({ }^{\circ} \mathrm{C}\right)\end{array}$ & $\begin{array}{l}6,65 \\
13,5 \\
33,5\end{array}$ & $\begin{array}{l}6,65 \\
13,5 \\
33,5\end{array}$ & $\begin{array}{l}6,66 \\
14,0 \\
34,0\end{array}$ & $\begin{array}{l}6,66 \\
14,0 \\
34,0\end{array}$ & $\begin{array}{l}6,64 \\
14,4 \\
34,0\end{array}$ & $\begin{array}{l}6,64 \\
14,4 \\
34,0\end{array}$ \\
\hline Durée de maturation (mn) & 120 & 120 & 120 & 120 & 120 & 120 \\
\hline $\begin{array}{l}\text { Addition d'agent coagulant } \\
\left({ }^{\circ} \mathrm{C}\right) \text { température du lait } \\
\text { Quantité (ml) } \\
\text { pH du lait } \\
\left.\text { Acidité du lait ( }{ }^{\circ} \mathrm{D}\right)\end{array}$ & $\begin{array}{l}32,0 \\
10 \\
6,38 \\
17,5\end{array}$ & $\begin{array}{l}32,0 \\
60 \\
6,38 \\
17,5\end{array}$ & $\begin{array}{l}32,0 \\
10 \\
6,49 \\
15,6\end{array}$ & $\begin{array}{l}32,0 \\
60 \\
6,48 \\
15,6\end{array}$ & $\begin{array}{l}30,0 \\
10 \\
6,48 \\
16,0\end{array}$ & $\begin{array}{l}30,5 \\
60 \\
6,48 \\
16,0\end{array}$ \\
\hline Prise après $(\mathrm{mn})^{*}$ & 5 & 5 & 18. & 16 & 18 & 14 \\
\hline $\begin{array}{l}\text { - Découpage* } \\
\text { pH du caillé }\end{array}$ & 61 & 61 & $\begin{array}{l}85 \\
6,25\end{array}$ & $\frac{85}{6,25}$ & $\begin{array}{l}83 \\
6,24\end{array}$ & $\begin{array}{l}83 \\
6,05\end{array}$ \\
\hline - Moulage* & 66 & 66 & 90 & 90 & 88 & 88 \\
\hline $\begin{array}{l}\text { - Premier retournement* } \\
\text { pH du caillé }\end{array}$ & $\begin{array}{r}109 \\
4,80\end{array}$ & $\begin{array}{r}114 \\
4,98\end{array}$ & $\stackrel{155}{5,30}$ & $\frac{155}{5,47}$ & $\stackrel{178}{5,52}$ & $\frac{153}{5,60}$ \\
\hline $\begin{array}{l}\text { - Deuxième retournement* } \\
\text { pH du caillé }\end{array}$ & $\begin{array}{r}224 \\
4,36\end{array}$ & $\underset{4,42}{224}$ & $\begin{array}{l}284 \\
4,75\end{array}$ & $\begin{array}{l}285 \\
4,74\end{array}$ & $\begin{array}{l}318 \\
4,52\end{array}$ & $\begin{array}{l}318 \\
4,50\end{array}$ \\
\hline
\end{tabular}

* Il s'agit du temps écoulé depuis l'addition du coagulant (en mn). 
ques mésophiles [4] (tab. 1) et maintenus à une température voisine de $34^{\circ} \mathrm{C}$. Quand l'abaissement de $\mathrm{pH}$ était jugé suffisant (de 6,6 à 6,5 environ) le lait était réparti dans deux bassines, à raison de $50 \mathrm{~kg}$ dans chaque, et additionné d'une quantité d'agent coagulant (présure ou extrait de Cynara cardunculus) telle que le temps de coagulation soit voisin dans les deux bassines (environ $15 \mathrm{mn}$ ). Ensuite la fabrication était conduite de la même façon pour le lot " essai " et le lot "témoin " selon une technique qui comportait un découpage grossier du caillé rapidement suivi d'un moulage à l'aide d'un multimoule. Le tableau 3 donne les principaux paramètres des trois essais réalisés. Au cours du premier essai on a utilisé plus de levain que pour les deux essais suivants et toutes les opérations de fromagerie ont été effectuées à un $\mathrm{pH}$ plus bas.

Après démoulage, les fromages étaient salés en saumure puis affinés pendant 10 à $15 \mathrm{j}$ dans un local à $12^{\circ} \mathrm{C}$ et $85 \mathrm{p} .100$ d'humidité relative et, ensuite, maintenus après emballage entre $4^{\circ} \mathrm{C}$ et $6^{\circ} \mathrm{C}$ pendant une période de 30 et $60 \mathrm{j}$.

GRUYÈRE : Les fabrications de Gruyère de Comté ont été effectuées à partir du lait cru selon la méthode traditionnelle. Le lait de fabrication était ensemencé à l'aide de suspensions concentrées congelées de bactéries lactiques thermophiles [5]. Le tableau 4 indique les principaux paramètres mesurés au cours de ces fabrications; le lait était coagulé sans maturation préalable.

Les fromages étaient affinés pendant 5 mois suivant le cycle de température habituel $\left(20 \mathrm{j}\right.$ à $12^{\circ} \mathrm{C}, 70 \mathrm{j}$ à $17^{\circ} \mathrm{C}$ et $60 \mathrm{j}$ à $\left.12^{\circ} \mathrm{C}\right)$.

\section{4) Méthodes d'analyse}

Les contrôles de fabrication ont été effectués en utilisant les méthodes suivantes :

a) Flore totale du lait : dénombrement sur milieu «Plate Count Agar DIFCO 0479-01 ». Incubation $48 \mathrm{~h}$ à $30^{\circ} \mathrm{C}$.

b) Coliformes : dénombrement sur «Désoxycholate Agar DIFCO 0273-01 ». Incubation $24 \mathrm{~h}$ à $37^{\circ} \mathrm{C}$.

c) Clostridium : dénombrement sur milieu au lactate de sodium [6].

d) Teneur en graisse du lait et du lactosérum : méthode butyrométrique Gerber.

e) Teneur en graisse du fromage : méthode butyrométrique Van Gulik.

f) Matières azotées totales $(\mathrm{N} \times 6,39)$ du lait et du lactosérum : méthode Kjeldahl.

g) Matière sèche du fromage : dessiccation à l'étuve à $100^{\circ} \mathrm{C}$ jusqu'à poids constant précédée, dans le cas du Camembert, d'une dessiccation sous vide pendant $16 \mathrm{~h}$ à température ambiante. 
TABLEAU 4. - Gruyère (conditions de fabrication)

\begin{tabular}{|c|c|c|c|c|c|c|}
\hline \multirow{2}{*}{ Essai } & \multicolumn{2}{|c|}{1} & \multicolumn{2}{|c|}{2} & \multicolumn{2}{|c|}{3} \\
\hline & Présure & $\begin{array}{c}\text { Cynara } \\
\text { cardunculus }\end{array}$ & Présure & $\begin{array}{c}\text { Cynara } \\
\text { cardunculus }\end{array}$ & Présure & $\begin{array}{c}\text { Cynara } \\
\text { cardunculus }\end{array}$ \\
\hline Quantité de lait (litres) & 525 & 525 & 530 & 530 & 530 & 530 \\
\hline $\begin{array}{l}\text { Addition d'agent coagulant : } \\
\text { Quantité (g ou ml) }\end{array}$ & $116 \mathrm{ml}$ & $132 \mathrm{~g}$ & $117 \mathrm{ml}$ & $132 \mathrm{~g}$ & $117 \mathrm{ml}$ & $132 \mathrm{~g}$ \\
\hline Prise après $(\mathrm{mn})^{*}$ & 30 & 28 & 31 & 30 & 30 & 30 \\
\hline Observations sur le lactosérum au décaillage & normal & grisâtre & normal & grisâtre & normal & grisâtre \\
\hline Température de chauffage $\left({ }^{\circ} \mathrm{C}\right)$ & 54 & 54 & 54 & 54 & 54 & 54 \\
\hline Temps total de fabrication $(\mathrm{mn})^{*}$ & 150 & 156 & 156 & 164 & 160 & 162 \\
\hline $\mathrm{pH} 6 \mathrm{~h}$ après mise sous presse & 5,44 & 5,30 & 5,58 & 5,40 & 5,50 & 5,40 \\
\hline $\mathrm{pH}$ au démoulage & 5,10 & 5,12 & 5,10 & 5,05 & 5,15 & 5,10 \\
\hline
\end{tabular}

* Il s'agit du temps écoulé depuis l'addition du coagulant (en mn). 
h) Azote total du fromage [7] et azote soluble dans l'acide trichloracétique à 4 p. 100 [3].

i) Electrophorèse du fromage : un échantillon de $9 \mathrm{~g}$ (Camembert) et de $6 \mathrm{~g}$ (Gruyère) était additionné de $25 \mathrm{ml}$ d'une solution d'urée $8 \mathrm{M}$ et agité jusqu'à dissolution. La matière grasse était alors éliminée par décantation. La solution était soumise à une électrophorèse sur gel d'amidon en urée et 2-mercaptoéthanol selon la méthode de Wake et Baldwin [8] modifiée par Schmidt [9].

Les contrôles f à i mentionnés ci-dessus étaient effectués dans le cas du fromage selon le schéma suivant : Camembert : a) caillé prélevé $4 \mathrm{~h}$ après l'emprésurage, b) au démoulage (24 h environ après l'emprésurage), c) au bout de 15,30 et 60 j. Gruyère : les mêmes prélèvements étaient effectués au premier retournement (environ $4 \mathrm{~h}$ après le début de la fabrication), à la sortie de presse (22 h environ après le début de la fabrication) et au bout de 1,3 et 5 mois d'affinage.

\section{5) Examens organoleptiques}

CAmembert : Les fromages âgés de 1 mois étaient soumis à l'appréciation d'un jury de dégustation qui procédait notamment à un test de différence (dégustation triangulaire).

GRUYÈRE : En cours d'affinage, en particulier au moment du changement de cave et après 5 mois d'affinage, les fromages (essais et témoins) ont été jugés par un collège d'experts, soit sur des échantillons prélevés à la sonde, soit après avoir été coupés.

\section{RESULTATS}

\section{1) Emploi de l'extrait de Cynara cardunculus}

L'utilisation de l'extrait de Cynara cardunculus ne comporte aucune difficulté particulière si ce n'est qu'en raison des quantités relativement importantes qui se sont avérées nécessaires pour obtenir les durées de coagulation normales, l'extrait (liquide et en poudre) communiquait au lait de fabrication, au lactosérum et au fromage, une couleur légèrement brunâtre, caractéristique, qui persistait pendant l'affinage chez les deux types de fromages.

\section{2) Propriétés du caillé au cours de la fabrication}

La fabrication du Camembert ne nécessite pas de travail du caillé et il n'a pas été fait d'observations particulières sur la différence entre le caillé obtenu avec la présure et celui obtenu avec l'extrait végétal si ce n'est que les quantités de caillé obtenues avec Cynara cardunculus étaient, pendant l'égouttage et au démoulage, nettement plus faibles qu'avec la présure.

Pour le Gruyère on a observé que le grain de caillé correspondant à l'extrait de "Cynara cardunculus » restait plus " mou " que le grain de caillé obtenu avec la présure. Néanmoins le fromager 
a) Camembert

\begin{tabular}{|c|c|c|c|c|c|c|c|c|}
\hline \multirow[b]{2}{*}{ Essai } & \multicolumn{2}{|c|}{1} & \multicolumn{2}{|c|}{2} & \multicolumn{2}{|c|}{3} & \multicolumn{2}{|c|}{ Moyenne } \\
\hline & Présure & $\begin{array}{c}\text { Cynara } \\
\text { cardun- } \\
\text { culus }\end{array}$ & Présure & $\begin{array}{l}\text { Cynara } \\
\text { cardun- } \\
\text { culus }\end{array}$ & Présure & $\begin{array}{l}\text { Cynara } \\
\text { cardun- } \\
\text { culus }\end{array}$ & Présure & $\begin{array}{c}\text { Cynara } \\
\text { cardun- } \\
\text { culus }\end{array}$ \\
\hline $\begin{array}{l}\text { Poids de fromage obtenu au démoulage } \\
\text { à partir de } 50 \mathrm{~kg} \text { de lait }(\mathrm{kg}) \\
\text { "Rendement en poids frais » pour } 100 \mathrm{~kg} \\
\text { de lait } \mathrm{R}_{1} \\
\text { "Rendement Cynara cardunculus » cor- } \\
\text { rigé } \mathrm{R}_{2} \\
\text { Teneur en substance sèche (p. } 100) \text { des } \\
\text { fromages frais }\end{array}$ & $\begin{array}{r}7,3 \\
14,6 \\
14,6 \\
40,9\end{array}$ & $\begin{array}{r}6,0 \\
12,0 \\
13,6 \\
45,6\end{array}$ & $\begin{array}{r}7,1 \\
14,2 \\
14,2 \\
43,0\end{array}$ & $\begin{array}{r}5,7 \\
11,4 \\
12,4 \\
46,0\end{array}$ & $\begin{array}{r}7,0 \\
14,0 \\
14,0 \\
42,7\end{array}$ & $\begin{array}{r}6,1 \\
12,2 \\
13,4 \\
46,1\end{array}$ & $\begin{array}{r}7,13 \\
14,26 \\
14,26\end{array}$ & $\begin{array}{r}5,93 \\
11,86 \\
13,1\end{array}$ \\
\hline \multicolumn{9}{|c|}{ b) Gruyère } \\
\hline \multirow[b]{2}{*}{ Essai } & \multicolumn{2}{|c|}{1} & \multicolumn{2}{|c|}{2} & \multicolumn{2}{|c|}{3} & \multicolumn{2}{|c|}{ Moyenne } \\
\hline & Présure & $\begin{array}{l}\text { Cynara } \\
\text { cardun- } \\
\text { culus }\end{array}$ & Présure & $\begin{array}{l}\text { Cynara } \\
\text { cardun- } \\
\text { culus }\end{array}$ & Présure & $\begin{array}{l}\text { Cynara } \\
\text { cardun- } \\
\text { culus }\end{array}$ & Présure & $\begin{array}{c}\text { Cynara } \\
\text { cardun- } \\
\text { culus }\end{array}$ \\
\hline $\begin{array}{l}\text { Quantité de lait transformée } \\
\text { Poids de fromage frais obtenu (kg) } \\
\text { "Rendement en poids frais " pour } 100 \mathrm{l} \\
\text { de lait } R_{1} \\
\text { Teneur en substance sèche (p. 100) de } \\
\text { fromages frais }\end{array}$ & $\begin{array}{l}525 \\
48,3 \\
9,20 \\
62,1\end{array}$ & $\begin{array}{l}525 \\
46,6 \\
8,87 \\
61,7\end{array}$ & $\begin{array}{l}530 \\
46,4 \\
8,75 \\
62,7\end{array}$ & $\begin{array}{l}530 \\
45,0 \\
8,49 \\
60,5\end{array}$ & $\begin{array}{l}530 \\
47,1 \\
8,88 \\
62,4\end{array}$ & $\begin{array}{r}530 \\
46,8 \\
8,83 \\
61,8\end{array}$ & $\begin{array}{l}\frac{530}{-} \\
8,94\end{array}$ & $\begin{array}{l}530 \\
- \\
8,73\end{array}$ \\
\hline
\end{tabular}


estimait que le travail en cuve devait avoir la même durée avec les deux enzymes.

Les fromages à l'extrait de "Cynara cardunculus " avaient une consistance plus molle à l'âge de $1 \mathrm{j}$ que les fromages à la présure et ils se déformaient nettement dès les premiers jours d'affinage en cave chaude à $17^{\circ} \mathrm{C}$.

\section{3) Poids des fromages et rendements}

CAmembert : Le poids de fromage obtenu par pesée au démoulage à partir de $50 \mathrm{~kg}$ de lait était toujours nettement plus élevé avec la présure de veau qu'avec l'extrait de "Cynara cardunculus». En exprimant ces résultats sous forme de "rendement " (poids de fromage obtenu à partir de $100 \mathrm{~kg}$ de lait), on obtenait un rendement moyen de $14,3 \mathrm{~kg}$ avec la présure et de $11,9 \mathrm{~kg}$ avec l'extrait de «Cynara Cardunculus ». Cette différence provenait en partie de la différence de teneur en matière sèche existant entre les fromages « présure » et les fromages "Cynara cardunculus ", ces derniers étant notablement plus secs (tab. 5 a). En ramenant les fromages "Cynara cardunculus" à la même teneur en substance sèche que les fromages " présure " selon Maubois et Mocquot [10], le rendement des fromages "Cynara cardunculus » passe de 11,9 à 13,1. La différence de $1,2(14,3-13,1)$ qui subsiste représente la perte de rendement imputable à l'extrait de "Cynara cardunculus ». Au lieu de $100 \mathrm{~kg}$ de fromage "présure » on obtient $91,6 \mathrm{~kg}$ de fromage "Cynara cardunculus " soit une perte de 8,4 p. 100 environ. Cette perte en fromage a pour conséquence un enrichissement du lactosérum en matière azotée. Ainsi, au cours d'un autre essai, effectué pour vérifier les résultats précédents, on a trouvé une teneur en matière azotée totale de 0,86 p. 100 dans le lactosérum séparé du caillé " présure " et de 1,14 p. 100 dans le lactosérum du caillé "Cynara cardunculus ».

GRUYÈRE : Le tableau $5 \mathrm{~b}$ montre que le rendement moyen en fromage était de 8,94 p. 100 avec la présure et de 8,73 p. 100 avec l'extrait de «Cynara cardunculus ». Contrairement au Camembert les fromages "Cynara cardunculus » étaient plus humides que les fromages "présure ». Si l'on ramène les fromages "Cynara cardunculus » à la même substance sèche que ces derniers, le rendement des fromages "Cynara cardunculus » devient égal à 8,56 p.100 en moyenne. La différence de rendement entre les deux types de fromages est de $8,94-8,56=0,38$, soit une perte de 4,25 p. 100 environ.

\section{4) Etude de l'évolution des matières azotées au cours de l'affinage}

Les figures 1 et 2 montrent l'évolution de la fraction « azote soluble " (NPN) au cours de l'affinage des deux types de fromages.

Dans le cas du Camembert (fig. 1) on observe déjà dans les fromages âgés de $1 \mathrm{j}$ une protéolyse plus marquée dans les fromages "Cynara cardunculus ». Au cours de la maturation et jusqu'à 1 mois, l'azote soluble augmente dans les fromages "Cynara cardunculus 》 mais son niveau rejoint celui que l'on observe dans les fromages " présure " à la fin de cette période. Dans les 30 jours suivants, 


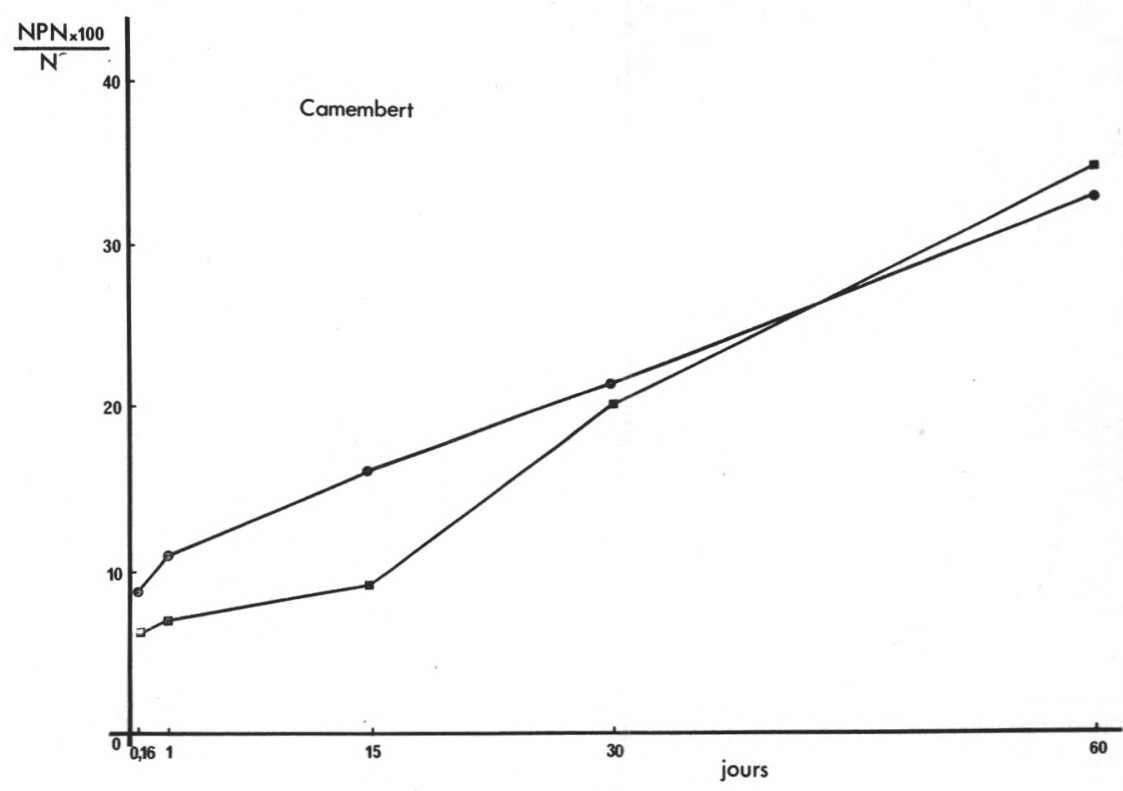

fig. 1

Protéolyse du fromage en cours d'affinage

- - Cynara cardunculus

- Présure

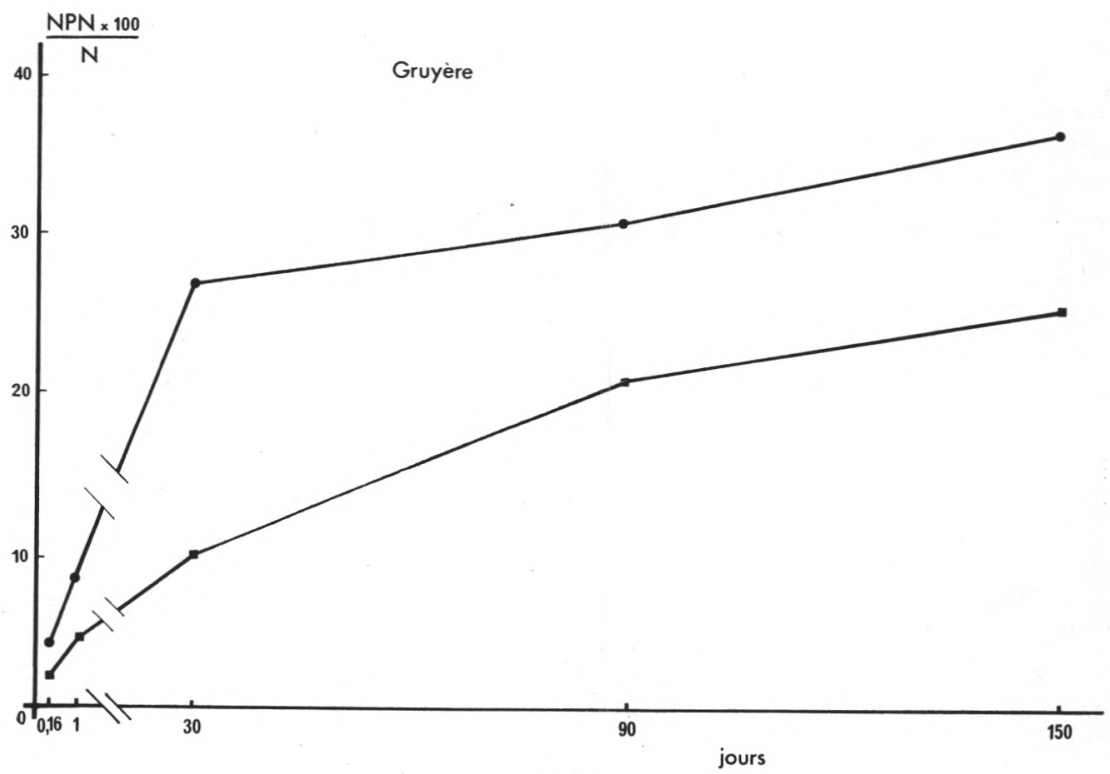

fig. 2

Protéolyse du fromage en cours d'affinage

- Cynara cardunculus 
la protéolyse continue à augmenter mais à peu près de la même façon pour les deux enzymes.

Dans le cas du Gruyère, la protéolyse est nettement plus prononcée dans le cas des fromages "Cynara cardunculus » que dans celui des fromages "présure " pendant toute la période étudiée. La protéolyse due à l'enzyme de "Cynara cardunculus » et celle qui est due à la présure augmentent au fur et à mesure que la maturation avance.

\section{5) Etude électrophorétique}

Si l'étude de l'évolution des substances azotées solubles des fromages en fonction du temps (fig. 1 et 2 ) donne un renseignement sur la vitesse d'apparition et la quantité globale de fragments peptidiques de petite taille libérés des caséines lors de la maturation, l'étude des diagrammes électrophorétiques obtenus pendant le même temps à partir des fromages (fig. 3 et 4 ) donne une indication sur l'évolution des différentes caséines de même que sur l'évolution des fragments de grande taille qui en proviennent.

Les principales constatations que l'on peut faire en comparant les diagrammes obtenus sur les fromages témoins (présure) et sur les fromages d'expérience sont les suivantes :

\subsection{Camembert (fig. 3).}

Une différence très importante se manifeste déjà au bout de $4 \mathrm{~h}$ entre les fromages "Cynara cardunculus " et les fromages " présure 》: la quasi-totalité des caséines majeures ( $\alpha_{\mathrm{si}}$ et $\beta$ ) a été attaquée dans les fromages "Cynara cardunculus ". Dans les fromages «présure », l'apparition de quelques bandes peu intenses témoignent d'une certaine protéolyse, qui laisse cependant intacte la presque totalité des deux caséines principales. De plus, les peptides qui apparaissent dans les deux types de fromages sont différents. Ceci témoigne d'une spécificité nettement différente des deux enzymes.

Dans les fromages fabriqués soit avec l'un, soit avec l'autre type d'enzyme, il n'y a pas d'évolution électrophorétique notable entre $4 \mathrm{~h}$ et $24 \mathrm{~h}$. Ceci paraît en contradiction avec l'évolution de l'azote soluble non protéique (NPN) qui augmente fortement durant cette période, notamment dans le cas des fromages "Cynara cardunculus" (fig. 1). Il faut cependant remarquer que, d'après la figure 1 et dans le cas des fromages "Cynara cardunculus » qui évoluent le plus rapidement, le NPN ne représente qu'une petite fraction de l'azote protéique total et les proportions de ce dernier ne changent de ce fait, pas beaucoup, de 91,4 à 89,4 environ. Ceci explique que l'influence au niveau de l'électrophorèse soit pratiquement nulle. 
Camembert

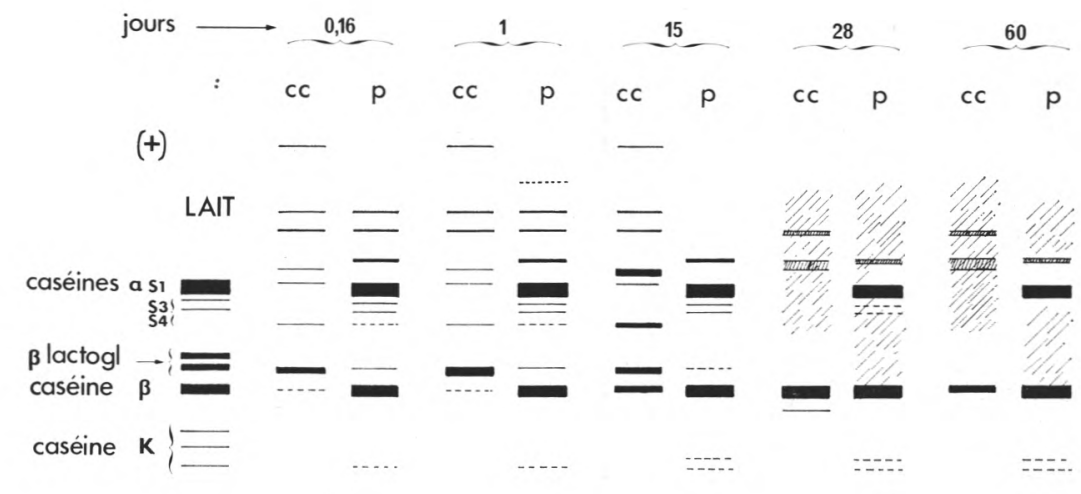

origine

$(-)$

para -

- caséine $\mathbf{K} \rightarrow$

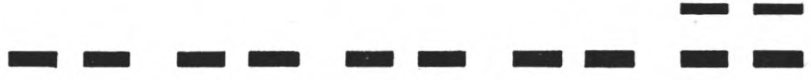

Gruyère

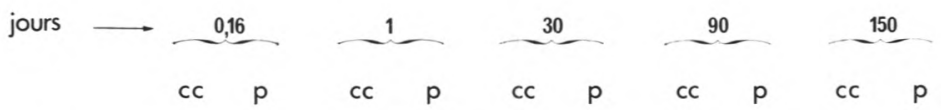

$(+)$

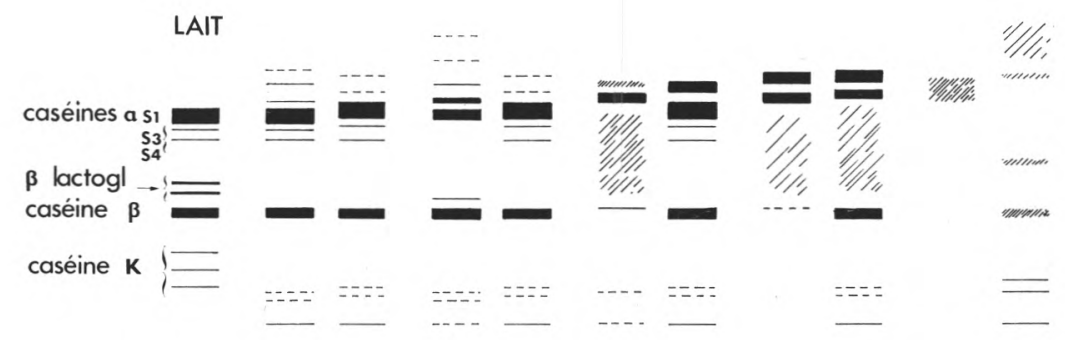

origine

$(-)$

para -

- caséine $\mathrm{K} \longrightarrow \longrightarrow$

fig. 3

Diagrammes électrophorétiques

cc : Cynara cardunculus

$\mathrm{p}$ : présure 
L'évolution électrophorétique des fromages « présure » est très faible jusqu'à $15 \mathrm{j}$. Par contre les électrophorèses réalisées au bout de 28 et 60 j montrent une dégradation plus importante des caséines, due sans doute à la libération des enzymes du Penicillium puisque les deux enzymes coagulantes utilisées ont vraisemblablement peu d'activité aux $\mathrm{pH}$ où se trouvent alors les fromages. Si cette dégradation se traduit en électrophorèse par l'apparition de quelques nouveaux composés, une proportion importante des caséines $\alpha_{\mathrm{s}_{1}}$ et $\beta$ reste encore apparemment intacte au bout de $60 \mathrm{j}$. Les enzymes du Penicillium semblent produire, à partir des caséines, directement de petits peptides non visibles par électrophorèse.

On observe une évolution similaire pour les fromages « Cynara cardunculus ". Cependant la différence entre les fromages de $1 \mathrm{j}$ et de 15 j est plus accentuée. Au bout de 28 j ou de $60 \mathrm{j}$ le fromage est nettement plus dégradé, mais cette dégradation est quantitativement peu différente de celle des fromages " présure ». Néanmoins les produits qui restent visibles par électrophorèse au bout de ces périodes sont différents selon que l'on examine les fromages fabriqués avec l'une ou l'autre enzyme.

En résumé, on peut dire que ce qui fait la différence (très importante) entre les fromages fabriqués soit avec l'une, soit avec l'autre enzyme, c'est une protéolyse rapide des caséines par l'enzyme de "Cynara cardunculus " pendant les premières heures. Pratiquement toutes les molécules de caséines $\alpha_{s i}$ et $\beta$ sont attaquées. A l'inverse une faible proportion de ces caséines a été touchée par la présure durant cette période. Par la suite, l'évolution devient assez semblable, pour l'un et l'autre type d'enzyme ; d'autres enzymes que les enzymes coagulantes intervenant alors.

\subsection{GRUYÈRE (fig. 3)}

L'évolution électrophorétique du Gruyère suit approximativement celle du Camembert mais la protéolyse des fromages « Cynara cardunculus » est plus lente. Au premier retournement (environ 3 h 30), il n'y a pas de différences significatives entre les fromages préparés avec l'une ou l'autre enzyme. Au bout de 1 j l'électrophorèse des fromages "présure " est inchangée. Celle des Gruyères "Cynara cardunculus " montre que la caséine $\beta$ n'est pas attaquée. Par contre environ 50 p. 100 de la caséine $\alpha_{\mathrm{S} 1}$ ont été touchés. L'électrophorégramme de $C$. cardunculus à $1 \mathrm{j}$ est voisin de celui des Gruyères "présure " au bout de 1 mois. Au bout de ce temps les fromages « Cynara cardunculus " apparaissent très fortement dégradés. La caséine $\beta$ a totalement disparu après 3 mois, alors qu'elle est encore très nettement visible pour les fromages " présure ». A la fin de l'affinage les deux types de fromages sont profondément dégradés. Il reste cependant des peptides de taille importante dans les fromages " présure ", alors que les fromages "Cynara cardunculus " en sont pratiquement dépourvus. 


\section{6) Qualités organoleptiques des fromages}

Camembert : Au moment de la dégustation, c'est-à-dire à l'âge de 1 mois environ, les fromages témoins (présure) étaient presque affinés " à cour ». Ceux de la première fabrication " coulaient " légèrement sous la croûte. Les fromages "Cynara cardunculus " étaient moins épais, plus secs et la couleur de leur pâte était légèrement brune.

Les dégustateurs interrogés sur les caractères de pâte et de goût des fromages (présentés de façon anonyme) étaient capables de distinguer de façon significative ceux qui avaient été préparés avec Cynara cardunculus et ceux qui avaient été préparés avec la présure. Le défaut de goût le plus fréquemment noté pour les fromages «Cynara cardunculus » était leur amertume.

GRUYÈRE : Les Gruyères témoins (présure) étaient des fromages possédant les caractères organoleptiques (aspect, consistance, arôme et goût) typiques du Gruyère. On notait toutefois que "l'ouverture " était rare et que les fromages présentaient des lainures. Les fromages "Cynara cardunculus » présentaient la consistance d'un beurre assez ferme, c'est-à-dire une consistance nettement plus molle que celle d'un Gruyère normal. L' " ouverture " était en général plus grosse et toujours plus abondante que celle des fromages témoins et la pâte ne présentait pas de lainure. Le goût de ces fromages de Gruyère était nettement amer.

\section{DISCUSSION}

En général le défaut le plus marqué, reconnu à tous les fromages que nous avons fabriqués avec l'extrait de "Cynara cardunculus ", était leur amertume. A ce sujet il convient de rappeler l'observation suivante : le fromage de Serra préparé au Portugal avec du lait de brebis coagulé par un extrait de "Cynara cardunculus " n'est pas amer. Les auteurs du présent travail et plus particulièrement l'un de nous (M. B.) ont eu la possibilité de s'assurer de ce fait sur divers échantillons de fromage Serra. Nous avons fait à Jouy-enJosas un essai de fabrication de fromage de type Camembert à partir de lait de brebis en utilisant l'extrait de " Cynara cardunculus " comme agent coagulant : les fromages obtenus n'étaient pas amers.

Par ailleurs, les fromages de lait de brebis ou de chèvre préparés avec la présure de veau ne présentent pas non plus le défaut d'amertume alors que ce défaut est assez souvent observé avec les fromages de lait de vache préparés avec la même présure de veau. 
Nos recherches en cours ont pour but de déterminer si ce fait est imputable ou non à des propriétés particulières des caséines de brebis et de chèvre qui ne donneraient pas naissance aux peptides amers formés, dans certaines circonstances, à partir de la caséine du lait de vache. D'autre part, comme suite aux observations de Portmann et Pierre [11] nous recherchons également si, au cours de la fabrication, la croissance des bactéries lactiques apportées par le levain est la même dans le cas des caillés et fromages de brebis et de chèvre que dans le cas du caillé et fromage de vache afin de voir si une multiplication moins importante des cellules bactériennes dans le fromage de chèvre ou de brebis pourrait expliquer la moindre fréquence de défaut d'amertume [12].

Quoiqu'il en soit, l'utilisation très ancienne de l'extrait de «Cynara cardunculus " pour la préparation de fromage de Serra semble indiquer que les peptides amers ne sont pas formés à partir de lait de brebis aussi souvent qu'ils le sont à partir de lait de vache.

Par ailleurs, la consistance très molle des Gruyères « Cynara cardunculus » (par comparaison avec les Gruyères témoins obtenus avec la présure de veau dont la consistance était tout à fait normale) souligne l'influence considérable qu'exerce l'enzyme utilisée pour la coagulation du lait sur la texture du fromage.

De toute façon, pour envisager l'emploi d'un extrait coagulant de "Cynara cardunculus " dans la fabrication de fromages à pâte molle, il serait nécessaire que des améliorations soient apportées dans la préparation de l'extrait coagulant afin de le rendre plus soluble (extrait en poudre) et moins coloré. Les fromages obtenus, bien que différents du type habituel, étaient appréciés par certains mais il est évident que la diminution du rendement observée avec l'extrait de «Cynara cardunculus » n'est pas favorable à l'utilisation de cet extrait comme substitut de la présure. En ce qui concerne le Gruyère, l'extrait de "Cynara cardunculus » ne permet pas de fabriquer un fromage ressemblant au modèle traditionnel. La pâte et le goût diffèrent complètement de ceux du produit traditionnel. Il ne serait pas impossible d'envisager avec l'extrait coagulant à base de "Cynara cardunculus " la fabrication d'un nouveau type de fromage, obtenu selon la technologie des fromages à pâte cuite.

Finalement on peut se demander si l'action protéolytique assez marquée de l'enzyme présente dans l'extrait de "Cynara cardunculus » ne pourrait pas être utilisée pour modifier les qualités organoleptiques de certains fromages, par exemple pour améliorer l'onctuosité de la pâte de l'Emmental pasteurisé, ou pour relever le goût des fromages de type Saint-Paulin.

Note : «Une étude comparée de l'activité enzymatique de trois variétés d'artichaut du genre "Cynara cardunculus L " sur la coagution du lait " a été publiée [13] depuis la rédaction du manuscrit. 


\section{Remerciements}

Nous remercions vivement $M$. Ribadeau-Dumas pour les conseils qu'il nous $a$ apportés au cours de ce travail et lors de la rédaction du manuscrit. Nous remercions également $M$. Furet pour la collaboration qu'il nous a prêtée.

\section{Ré s u m é}

Un extrait coagulant, obtenu à partir des fleurs de "Cynara cardunculus L. » et utilisé traditionnellement au Portugal pour la fabrication des fromages de Serra et de Serpa, a été comparé à la présure de veau en fabrication de fromages de Camembert et de Gruyère.

Le poids de fromage frais ramené à la même teneur en eau et obtenu à partir du même poids de lait était plus faible d'environ 8,4 p. 100 en fabrication de Camembert et 4,2 p. 100 en fabrication de Gruyère lorsque l'extrait de "Cynara cardunculus L. " était utilisé au lieu de la présure de veau.

La mesure de la protéolyse en cours d'affinage ainsi que l'étude électrophorétique des caillés et des fromages montraient que l'extrait de "Cynara cardunculus L. " attaquait les protéines du lait et en particulier les caséines $\alpha_{s_{1}}$ et $\beta$ beaucoup plus rapidement et plus complètement que la présure dans les deux types de fromage.

Parallèlement, les caractères organoleptiques des fromages préparés avec l'extrait de "Cynara cardunculus L. " différaient nettement de ceux des fromages préparés avec la présure de veau en raison d'une consistance plus molle dans le cas des fromages de Gruyère et d'une amertume très prononcée pour les deux types de fromage. L'importance de ce dernier défaut qui n'est pas fréquemment rencontré dans les fromages préparés au Portugal à partir de lait de brebis avec l'extrait de "Cynara cardunculus L. " suggère des différences dans l'aptitude des caséines de brebis et de vache à donner des peptides amers sous l'action d'enzymes protéolytiques.

\section{S u $\mathrm{m} \mathrm{m}$ a r y}

An extract of coagulant obtained from the flowers of « Cynara cardunculus L. " and used traditionnally in Portugal for the manufacture of cheese of Serra and Serpa types, has been compared with calf rennet in the manufacture of Camembert and Gruyère cheese.

The weight of fresh cheese adjusted to the same moisture content and obtained from the same amount of milk was lower 
by 8.4 p. 100 in the case of the Camembert cheese and by 4.2 p. 100 in the case of the Gruyère cheese when the "Cynara cardunculus L. " extract replaced calf rennet.

The degree of proteolysis, observed during ripening of the curd and cheese by electrophoresis studies, showed that the "Cynara cardunculus $\mathrm{L}$. " extract degraded $\alpha_{\mathrm{S} 1}$ and $\beta$-caseins more rapidly and to a greater extent than the rennet in the two types of cheese.

Similarly the organoleptic characteristics of cheese prepared with the "Cynara cardunculus L. " extract were obviously different from those of the cheese made with the calf rennet due to the softer consistency of the Gruyère cheese and the very pronounced bitter flavour of the two types of cheese.

Reçu pour publication en septembre 1975.

\section{Références}

[1] Vieira de Sa (F.), Reis Machado (B.), Rafael Pinto (O. P.), Vicente da Cruz (I.M.), Dias Carneiro (M.J.), Antunes Barbosa (M.M.) et Costa Reis (M.M.). (1970). - Maturaçao em queijo de ovelha-serra e serpa. Instituto Nacional de Investigaçao Industrial. Quimica e Biologia. Lisboa-6.

[2] Christen (C.) et Virasoro (E.) (1935). - Le Lait, 15, 354.

[3] Vieira de SA (F.) and Barbosa (M.) (1972). - J. Dairy Res., 39, 335.

[4] Accolas (J. P.) et Auclair (J.) (1967). - Le Lait, 47, 253.

[5] Valles (E.) et Mocouot (G.) (1968). - Le Lait, 48, 631.

[6] Bergère (J. L.), Bienassis (G.), Hermier (J.), Mocouot (G.), Gouet (Ph.), Gorrot (G.) et Zelter (S. Z.) (1971). - Rev. Lait. Franç., 293, 967.

[7] Kosikowski (F.) (1966). - In Cheese and Fermented Milk Foods. Edwards Brothers, Inc. Ann. Arbor, Michigan, 350-351.

[8] Wake (R. G.) and Baldwin (R. L.) (1961). - Biochim. Biophys. Acta, 90, 411.

[9] Schmidt (D. G.) (1960), - Biochim. Biophys. Acta, 90, 411.

[10] Maubois (J. L.) et Mocouot (G.) (1967). - Rev. Lait. Franç., 239, 15.

[11] Portmann (A.) et Pierre (A.) (1973). - Rev. Lait. Franç., 312, 629.

[12] Lowrie (R. J.), Lawrence (R. G.), Pearce (L. E.) and Richards (E. L.) (1972). - N.Z.J. Dairy Sci. Techn., 7, 44.

[13] Tsouli (J.) (1974). - Le Lait, 54, 415. 